\title{
The value of 3D and 4D assessments of the fetal heart
}

This article was published in the following Dove Press journal:

International Journal of Women's Health

15 May 2014

Number of times this article has been viewed

\section{Edward Araujo Júnior \\ Liliam Cristine Rolo \\ Luciane Alves Rocha \\ Luciano Marcondes \\ Machado Nardozza \\ Antonio Fernandes Moron}

Department of Obstetrics, Federal University of São Paulo (UNIFESP), São Paulo, Brazil
Correspondence: Edward Araujo Júnior Department of Obstetrics, Federal University of São Paulo (UNIFESP), Rua Carlos Weber, 956, apto II 3 Visage, Vila Leopoldina, São Paulo, SP, CEP 05303-000, Brazil Tel/Fax +55 II 37965944

Email araujojred@terra.com.br
Abstract: The objective of this review was to demonstrate the main tools of three- and four-dimensional ultrasonography, using the spatiotemporal image correlation software and its respective applications for assessing the fetal heart and its vascular connections, along with its potential contribution towards screening for congenital heart diseases. Today, conventional, two-dimensional, echocardiography continues to be the gold standard for diagnosing congenital heart diseases. However, recent studies have demonstrated that spatiotemporal image correlation offers some advantages that boost two-dimensional accuracy in detecting congenital heart diseases, given that the fetal heart assessment can be completed in the absence of the patient (offline) and be discussed by different examiners. Additionally, data volumes can be sent for analysis in reference centers via internet links. Spatiotemporal image correlation also enables direct measurement of heart structures in rendering mode, such as the interventricular septum and the annulus of the atrioventricular valves. Furthermore, it enables assessment of cardiac function when used in association with the virtual organ computer-aided analysis software, thus making it possible to calculate the total systolic function, ejection fraction, and cardiac output.

Keywords: fetus, screening, congenital heart disease, echocardiography, three- and fourdimensional ultrasound, spatiotemporal image correlation

\section{Introduction}

Heart defects are the most common congenital malformations of fetuses, with incidence six times greater than chromosome abnormalities and four times greater than neural tube defects. ${ }^{1}$ The prenatal incidence of congenital heart disease (CHD) ranges from $2.4 \%-52 \% .^{2-7}$ This enormous variability occurs because of the policies adopted in different countries. The detection rate for CHDs is much higher in regions where it is obligatory to perform at least one fetal echocardiogram during pregnancy. ${ }^{8}$ On the other hand, it has been seen that the postnatal incidence ranges from $0.3 \%-1.2 \%$ of live births. ${ }^{9,10}$ This decrease between the prenatal and postnatal rates can be explained by the fact that many countries permit termination of pregnancy in cases of congenital malformations. ${ }^{8}$

Fetal echocardiographic examination emerged almost 40 years ago and, since the outset, it has been recommended that only fetuses in pregnancies at high risk of CHDs should undergo this examination. ${ }^{11}$ On the other hand, over the years, it has been seen that many CHDs also occur in fetuses in pregnancies at low risk. ${ }^{12}$ Thus, some European groups started to encourage the use of this examination for all pregnant women. However, because of the lack of specialist professionals within this field, the idea of "screening" for CHDs was introduced in the 1980s. The aim was to improve 
the detection of CHDs through training for obstetricians such that they would be able to perform examinations at some basic cardiac levels during morphological ultrasound examinations. ${ }^{12}$

In addition to the growth in importance of early diagnosis for CHDs, there has also been great technological development. For many years, CHDs were diagnosed solely by means of conventional two-dimensional (2D) echocardiography, but then, in the mid-1990s, three-dimensional (3D) ultrasonography came into existence. This was followed, at the beginning of the 2000s, by new software called spatiotemporal image correlation (STIC). This software was initially launched for use in the Voluson ${ }^{\mathrm{TM}} 730$ Expert device (GE Healthcare, Zipf, Austria), which enables acquisition of volumetric data on the fetal heart and its vascular connections. The images can be evaluated both in multiplanar mode and in rendered mode. The images can also be observed either in static form (3D) or in movement (four-dimensional [4D]), through a sequence of images that simulates a complete cardiac cycle (cineloop)..$^{5-7,13-15}$

The evolution of 3D/4D ultrasonography has created the opportunity to demonstrate fetal heart anatomy with less difficulty, making a close correlation with its vessels and structures. STIC has resulted from the constant search for methodologies that are more accurate for early diagnosis of the CHDs that are responsible for high neonatal morbidity and mortality.

Unlike 2D assessments, in which the cardiac structural analysis needs to be done at the time of the examination, STIC makes it possible to gather heart volume data and store it, which enables subsequent offline analysis by different examiners, at different times, and even remotely (via an internet link). ${ }^{16}$ Moreover, it enables 3D reconstruction of the image, which facilitates identification and comprehension of different heart malformations. Another interesting advantage of this method is the possibility of teaching heart anatomy more didactically to professionals involved in this field, given that this organ can now be viewed in 3D/4D.

The innovation that the STIC technology represents has given rise to the development of many studies that have gradually made this approach attractive for obstetric practice. This review covers the technique of acquiring STIC data volumes, assessment methods, and post-processing techniques, and their potential applicability in screening for CHDs.

\section{Technique for acquiring STIC data volumes}

Before acquisition of volumetric data, adjustments to the 2D parameters (dynamic range, filter, enhance, and gain) should be made in order to optimize the quality of the images obtained. The volumetric data should preferentially be acquired when the fetus is at rest, with the pregnant woman holding her breath for a few seconds. In addition, the image acquisition angle should be preselected: this can range from 10-45 degrees according to the gestational age. Lower angles are reserved for early gestational ages, whereas in the second and third trimesters, the angle ranges from 20-25 degrees and 35-40 degrees, respectively. The sweep duration can range from 7.5-15 seconds, and longer durations are always preferable for obtaining images of better resolution, with the exception of very active fetuses, in which case a shorter time is beneficial for data acquisition. ${ }^{17}$

The sweep can be done via either the abdominal or the endovaginal route (the latter is for the initial stage of gestation or for obese pregnant women $)^{18}$ in $3 \mathrm{D}$ or 4D. However, only 4D allows storage of the cardiac cycle, thereby enabling subsequent real-time analysis on fetal heart movement using the cineloop technique. ${ }^{13-15}$

An apical or transverse plane through the four chambers of the heart is preferable, with sweeps performed as transverse sections through the fetal thorax or abdomen, ideally with the fetal spine positioned at 6 o'clock, and always seeking to avoid sections in which the spine is between 11 o'clock and 1 o'clock because of the acoustic shadows. ${ }^{17}$ However, it is important to emphasize that sagittal sweeps may favor assessments of the aortic and ductal arches and the venous connections of the heart. ${ }^{19}$

Subsequently, so that the examiner responsible for the offline analysis on the heart volume data can ascertain the real position of the heart chambers in relation to the fetal axis (right and left sides), all the heart volume data should be stored in accordance with the current standards, ie, in cephalic presentation, considering that the cardiac side corresponds to the fetal side, which thus differs from the pelvic presentation, in which the sides are opposite..$^{20}$

Automatically, after data capture in the plane of the four chambers in $3 \mathrm{D}$ or $4 \mathrm{D}$, the device supplies images in the three orthogonal planes (axial, sagittal, and coronal), in multiplanar mode.

Proper acquisition of heart volume data is essential for correct analysis of the fetal heart. After volume data capture, image post-processing is required, in which cardiac planes and vascular images are reconstructed. The quality of this post-processing depends on whether the volume data acquisition was of good quality, and on the technicians' knowledge, which will be described below. 


\section{Multiplanar mode of STIC}

After the volume data has been obtained in the plane of the four heart chambers, the device automatically supplies the three orthogonal planes, in multiplanar mode: axial, sagittal, and coronal.

In multiplanar mode, the axial plane (plane A) supplies the specific four-chamber slice, while the other cardiac slices are seen in the sagittal plane (plane B) and in the coronal plane (plane C). Each orthogonal plane can be manipulated around the $\mathrm{x}-, \mathrm{y}-$, and $\mathrm{z}$-axes, and additionally, there is the possibility of movement in the craniocaudal direction through the "ref slice" key. Some systematizations have already been established, so as to obtain the outflow routes from the ventricle, along with the ductal and aortic arches. ${ }^{13-15}$

To obtain the outflow route for the major vessels, the technique proposed by Gonçalves et $\mathrm{al}^{14}$ was used, ie, plane A of the STIC volume should be rotated around the z-axis so that the base of the heart is arranged at 6 o'clock and the reference point is displaced to the crux of the heart. Also in plane $\mathrm{A}$, the volume should be rotated in the z-axis by 30 degrees to the left and the reference point should be displaced to the midpoint of the ventricular septum. By slightly rotating plane $\mathrm{A}$ in the $\mathrm{y}$-axis, continuity is thus opened between the ventricular septum and the anterior wall of the aorta. The reference point should then be displaced to below the aortic valve, thereby obtaining the outflow route of the left ventricle in plane $\mathrm{A}$ and the outflow route of the right ventricle in plane $\mathrm{B}^{14}$ (Figure 1).

To evaluate the aortic and ductal arches, the techniques proposed by Espinoza et $\mathrm{al}^{21}$ or by DeVore et $\mathrm{al}^{22}$ can be used. Both of these are based on the four-chamber plane

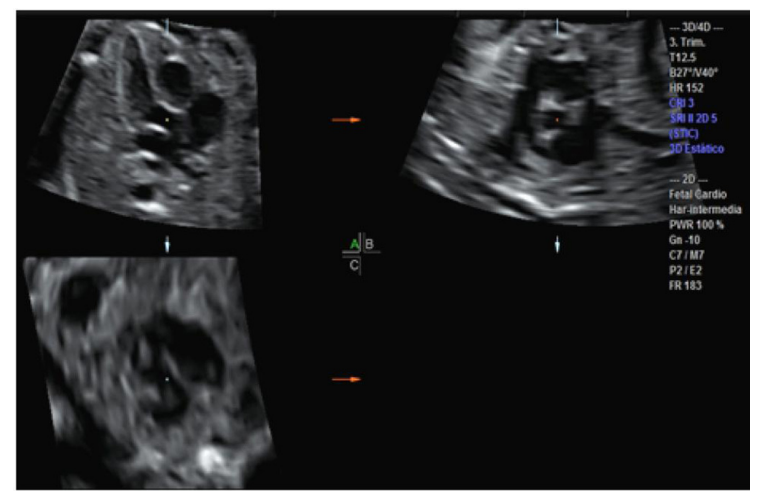

Figure I Technique of Gonçalves et al $^{14}$ for obtaining the outflow routes of the ventricles. Images in the three orthogonal planes of the fetal heart are obtained using the multiplanar mode of spatiotemporal image correlation, on the grey scale.

Notes: Upper left: axial plane (plane A) showing the outflow route of the left ventricle; upper right: sagittal plane (plane B) showing the outflow route of the right ventricle; lower left: coronal plane (plane C). for volume data acquisition. According to the technique proposed by Espinoza et al, ${ }^{21}$ the aortic and ductal arches are obtained as follows: keep plane A positioned with the base of the heart close to 6 o'clock, as defined earlier, and rotate plane A around the $\mathrm{z}$-axis until the crux of the heart is put into alignment with the descending aorta. The reference point should be displaced as far as the crux of the heart. In this manner, the ductal arch in plane B is obtained automatically. In displacing the reference point to the descending aorta in plane $\mathrm{A}$, it can be seen that in plane $\mathrm{C}$, the aorta is viewed longitudinally. Thus, plane $\mathrm{C}$ is then slightly rotated in the z-axis so that the aorta is displayed horizontally. In this manner, the aortic arch is obtained automatically in plane B (Figure 2). The second technique that can also be used is the one proposed by DeVore et $\mathrm{al}^{22}$ from the four-chamber plane in plane $\mathrm{A}$, which has already been standardized, and the reference point located at the crux of the heart, by moving the volume in the caudocranial direction until the plane of the three vessels and trachea is viewed. At this moment, the reference point is displaced to the pulmonary artery and plane $\mathrm{A}$ is moved around the z-axis until the pulmonary artery is put into a vertical orientation and aligned with the spine of the fetus. In this manner, the ductal arch is automatically obtained in plane B. In displacing the reference point to the aorta and moving plane $\mathrm{B}$ around the $\mathrm{z}$-axis until the aorta is made vertical and aligned with the spine of the fetus, the aortic arch is automatically obtained in plane B (Figure 3).

On a grey scale, STIC provides an assessment of outflow routes for the right and left ventricles and aortic and ductal arches. ${ }^{23}$ However, for defects of the interventricular septum and for assessing the crossing of the major vessels of the heart, association with color Doppler enables a more detailed analysis

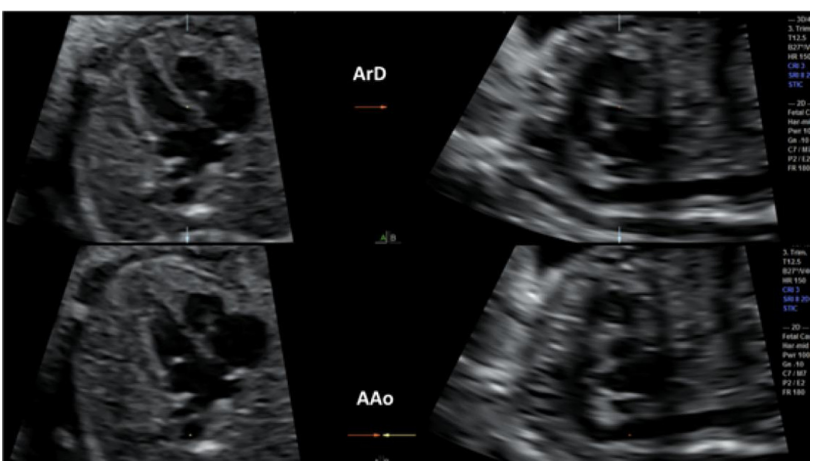

Figure 2 Technique of Espinoza et $\mathrm{a}^{21}$ for obtaining the aortic and ductal arches from the four-chamber plane of volumetric acquisition of spatiotemporal image correlation. With axial plane A positioned with the cardiac base close to 6 o'clock, the ductal arch is viewed in the sagittal plane when the reference point is positioned at the crux of the heart. The aortic arch is viewed in the sagittal plane when the reference point is moved to the descending aorta.

Abbreviations: ArD, ductal arch; AAo, aortic arch. 


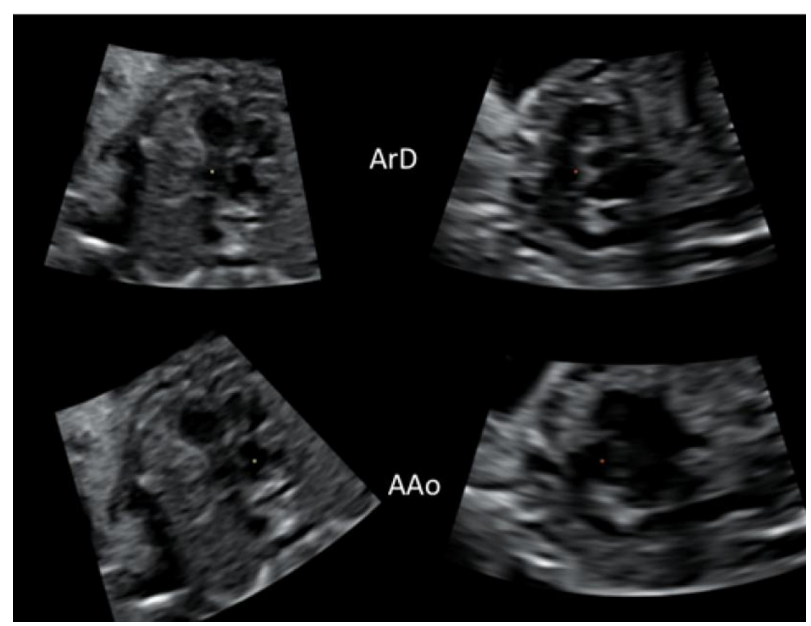

Figure 3 Technique of DeVore et $\mathrm{al}^{22}$ for obtaining the aortic and ductal arches from the plane of three vessels and trachea. With the axial plane A positioned in the three vessels and trachea, the ductal arch is viewed in the sagittal plane when the reference point is positioned in the pulmonary artery and the volume is rotated around the z-axis until the pulmonary artery is put into a vertical orientation and aligned with the fetal spine. The aortic arch is viewed in the sagittal plane when the reference point is displaced to the aorta and the volume is rotated around the $z$-axis until the aorta is put into a vertical orientation and aligned with the fetal spine. Abbreviations: ArD, ductal arch; AAo, aortic arch.

of these structures. ${ }^{24}$ In these cases, there will always be a need for activated color Doppler during volume data capture.

Thus, in selecting the region of interest (green line), positioned in plane B anteriorly (pulmonary artery) to posteriorly (aorta and ventricles), it is possible to obtain the crossing of the major vessels of the heart (aorta and pulmonary artery), in a rendered image. To perform rendering of the heart chambers after data capture, the region of interest should be positioned in plane $\mathrm{B}$, as a thin slice, from right to left.

\section{Rendering mode of STIC}

Through the rendering mode of STIC, cardiac texture can be evaluated, with identification of the chambers and valves, including the close correlation with vessels. In this application, cardiac movement can also be analyzed throughout the cycle, with detailed monitoring of the contraction and relaxation of the chambers (systole and diastole) and the opening and closing of the valves and annuli, and even identifying the papillary muscles and tendinous cords. In addition, STIC makes it possible to measure the heart structures that have already been described in studies that have determined the normal values for the tricuspid and mitral valve areas and septal area in fetuses. ${ }^{25-28}$

\section{Tomographic ultrasound imaging}

Tomographic ultrasound imaging is a technique within STIC that makes it possible to obtain all the parallel axial planes of the heart, from the abdomen to the apex of the thorax, with images similar to computed tomography. Through algorithms developed for obtaining the usual planes (four chambers, five chambers, three vessels and trachea, outflow routes of the ventricles, and longitudinal aortic and ductal arches), it helps in indentifying $\mathrm{CHDs}^{29}$ (Figure 4).

\section{Inversion mode and B-flow imaging}

Inversion mode is a technique in which analysis on fluid structures is performed by inverting the voxels of the grey scale. Thus, anechoic structures (heart chambers, vessel lumens, stomach, bladder, and renal pelvis) become echogenic, while structures that are normally echogenic (bones) become anechoic. ${ }^{17}$ In this manner, the technique adds power to identifying cardiac abnormalities, especially vascular connections, thus enabling analysis on the relationships between vessels, calibers, and positioning, and allowing reconstruction of heart chambers, aortic and ductal arches, and abnormalities of venous connections. . $^{17,30}$

The technique known as B-flow imaging improves weak signals reflected from the blood and suppresses strong signals from surrounding structures. It shows high sensitivity and does not depend on the angle (thus differing from color Doppler), which makes it possible to identify large and small vessels, including those of small caliber and low flow velocity, such as the pulmonary veins. ${ }^{31}$ In this manner, in addition to detecting abnormalities of the pulmonary venous return, ${ }^{31}$ it may improve identification of the vascular rearrangements present in CHDs. ${ }^{32}$

\section{Four-chamber view and swing technique}

This is a recent and promising type of acquisition technology featured in the latest ultrasonography devices. It has already

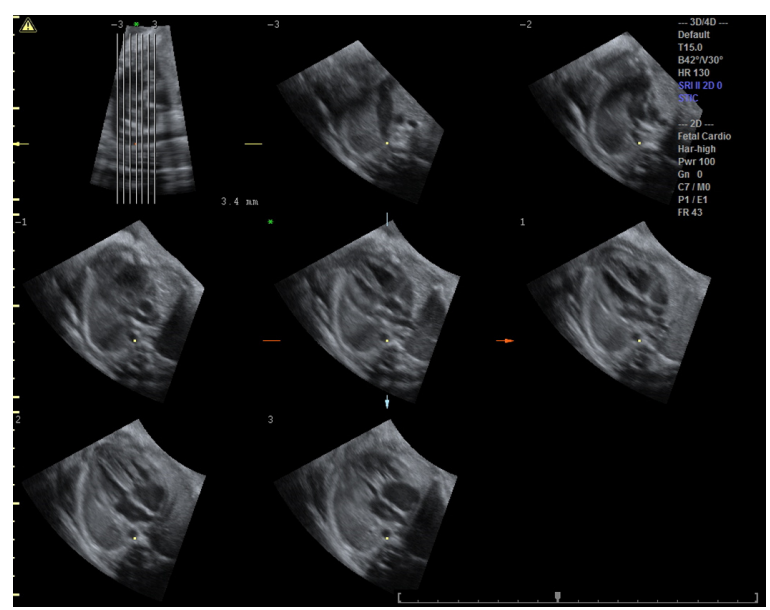

Figure 4 Tomographic ultrasound imaging showing parallel slices of cardiac planes along the fetal thorax, thus demonstrating the planes of three vessels and trachea, five chambers, and four chambers. 
been tested on heart volumes obtained by means of STIC, using the OmniView software (GE Healthcare). It allows identification of a variety of sequential planes of interest for echocardiographic evaluation, from longitudinal lines that are drawn manually on the planes of the aortic and ductal arches: line one - plane on the three vessels and trachea; line two - plane of the five chambers and longitudinal plane of the aorta; line three - plane of the four chambers; and line four "swing" - plane of the three vessels and trachea, plane of the five chambers and longitudinal plane of the aorta, and plane of the four chambers and stomach. ${ }^{33}$

\section{Fetal cardiac function by means of STIC}

STIC also makes it possible to evaluate cardiac function through measuring both the volumes of the ventricles in association with the virtual organ computer-aided analysis software, and through the movement mode (M mode). Quantification of the volumes of the ventricles during systole and diastole may enable calculation both of the systolic volume and of the ejection fraction and cardiac output. ${ }^{34-37}$ The M mode of STIC is another way of estimating the ejection fraction of the fetus, from measurements of the systolic and diastolic lengths of the ventricles, ${ }^{38}$ given that its efficacy for evaluating cardiac function in fetuses with hydrops has already been proven (Figure 5). ${ }^{39}$

\section{Assessment of CHDs by means of STIC}

The STIC software is only present in sophisticated ultrasound devices, which raises the cost and makes adherence to the technique difficult. ${ }^{40}$ However, many studies have already demonstrated that STIC favors and boosts detection of CHDs, thereby raising the diagnostic accuracy of conventional 2D echocardiography. ${ }^{24,41-43}$ So far, there have not been any studies in the literature that would make it possible to affirm that the STIC technology is superior to or replaces 2D echocardiography. Nevertheless, because it is less dependent on the operator, ${ }^{19}$ who only becomes capable of collecting heart volume data after training, and because of the possibility of having the data remotely analyzed by specialists at referral centers, the methodology becomes attractive and can contribute towards screening for CHDs at locations without fetal cardiology and pediatric specialists.

\section{STIC and HDlive}

Recently, new software named HDlive (GE Healthcare) has become available in the Voluson E8 ultrasound machine (GE Healthcare). HDlive is a new technique for surface designs,

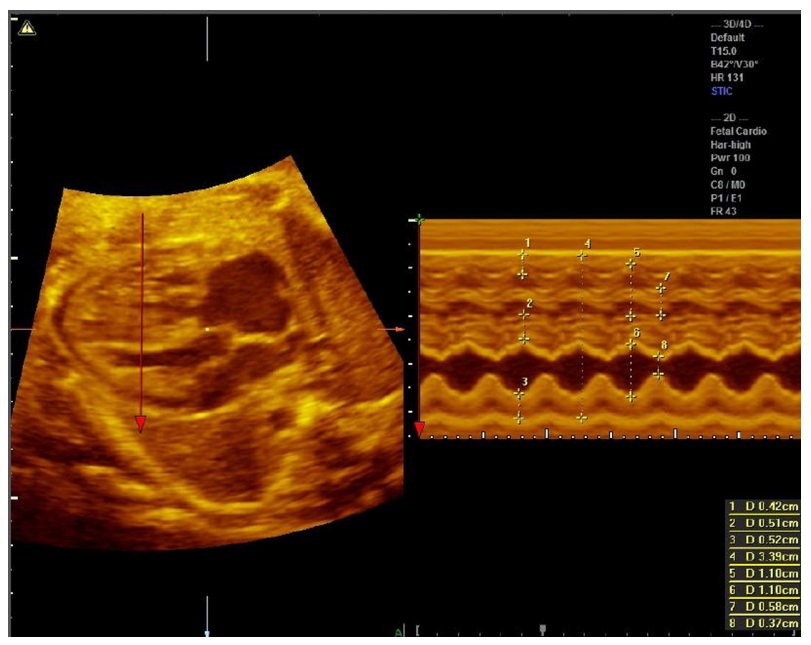

Figure $5 \mathrm{M}$ mode of spatiotemporal image correlation showing measurements of fetal cardiac function. I) Thickness of the wall of the left ventricle; 2) thickness of the interventricular septum; 3 ) thickness of the wall of the right ventricle; 4) external diameter of the two ventricles; 5 ) internal diameter of the left ventricle at the end of diastole; 6) internal diameter of the right ventricle at the end of systole; 7) internal diameter of the left ventricle at the end of systole; 8 ) internal diameter of the right ventricle at the end of systole.

in which the operator implements light settings to create depth effects by means of appropriate lighting and shading of the images. ${ }^{44}$

STIC-HDlive rendering is a new algorithm for assessing fetal heart structures similarly to other fetal structures. This new algorithm makes it possible to assess the standard fetal echocardiography views like the four-chamber and ventricle outflow views (Figure 6). ${ }^{45}$ Furthermore, this technique enables reconstruction

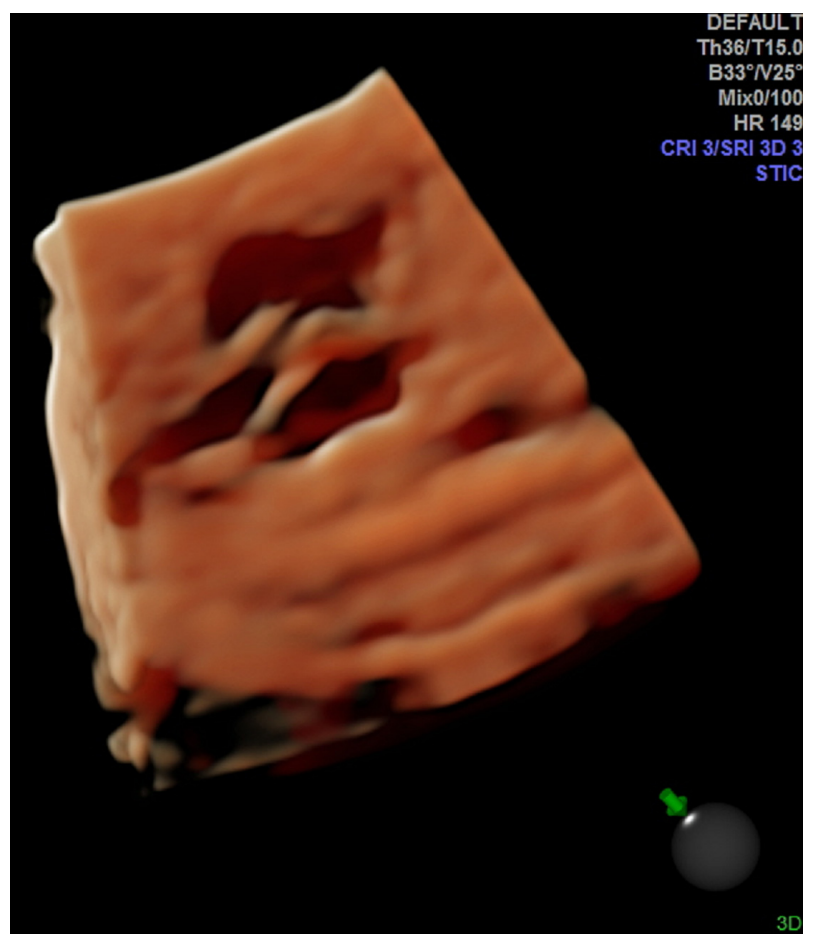

Figure 6 Spatiotemporal image correlation with HDlive in rendering mode, showing the plane of left ventricle outflow. Illumination incident at II o' clock. 
of the entire fetal heart and its connections. A recent study assessed four normal and three abnormal fetal heart conditions (Ebstein's anomaly, hypoplastic left heart syndrome, and tetralogy of Fallot). ${ }^{46}$ It was reported that STIC-HDlive enabled realistic sensing of each leaflet of the atrioventricular valves. In the case of Ebstein's anomaly, natural and anatomically realistic images of significantly low attachment of the tricuspid valve and the atrialized portion of the right ventricle were obtained. In the case of hypoplastic left heart syndrome, thickened tricuspid and dysplastic pulmonary valves were clearly revealed. In the case of tetralogy of Fallot, the overriding aorta and ventricular septal defects were realistically depicted. ${ }^{46}$ In another article, the same authors made a reconstruction of a normal fetal heart showing the four-chamber view and the left ventricle and descending aorta. They reported that HDlive differed from conventional rendering methods because it uses a fixed virtual light source that calculates the propagation of light through skin and tissue. Operators can freely select the light source at any angle relative to the ultrasound volume, to enhance anatomical details. ${ }^{47}$

\section{Conclusion}

Acquisition of fetal heart data by means of 3D/4D ultrasonography using the STIC software makes it possible to identify heart structures as a 4D cine sequence containing information on a complete cardiac cycle, thereby uniting the spatial and temporal information. The assessment can be in either multiplanar or rendering mode, with or without associated color Doppler, tomographic ultrasound imaging, inversion mode, or B-flow imaging. In this manner, the cardiac assessment can be completed in the patient's absence, given that the cardiac volume can be analyzed offline and by different examiners. This boosts the accuracy of 2D echocardiography for diagnosing CHDs. STIC in rendering mode enables direct measurement of the annuli of the atrioventricular valves and the interventricular septum. Furthermore, it allows assessment of cardiac function, when done in association with the virtual organ computer-aided analysis software, in order to calculate the total systolic volume, ejection fraction, and cardiac output. Thus, it can be stated that $3 \mathrm{D} / 4 \mathrm{D}$ STIC is a very promising tool, if good-quality and complete volumetric data acquisition is performed on the fetal heart that is under examination.

\section{Disclosure}

The authors report no conflicts of interest in this work.

\section{References}

1. Carvalho JS, Mavrides E, Shinebourne EA, Campbell S, Thilaganathan B. Improving the effectiveness of routine prenatal screening for major congenital heart defects. Heart. 2002;88(4):387-391.
2. Friedberg MK, Silverman NH, Moon-Grady AJ, et al. Prenatal detection of congenital heart disease. J Pediatr. 2009;155(1):26-31.

3. Yu Z, Xi Y, Ding W, et al. Congenital heart disease in a Chinese hospital: pre- and postnatal detection, incidence, clinical characteristics and outcomes. Pediatr Int. 2011;53(6):1059-1065.

4. Ozkutlu S, Akça T, Kafali G, Beksaç S. The results of fetal echocardiography in a tertiary center and comparison of low- and high-risk pregnancies for fetal congenital heart defects. Anadolu Kardiyol Derg. 2010;10(3):263-269.

5. Lee JE, Jung KL, Kim SE, et al. Prenatal diagnosis of congenital heart disease: trends in pregnancy termination rate, and perinatal and 1-year infant mortalities in Korea between 1994 and 2005. J Obstet Gynaecol Res. 2010;36(3):474-478.

6. Galindo A, Herraiz I, Escribano D, Lora D, Melchor JC, de la Cruz J. Prenatal detection of congenital heart defects: a survey on clinical practice in Spain. Fetal Diagn Ther. 2011;29(4):287-295.

7. Clur SA, Van Brussel PM, Mathijssen IB, Pajkrt E, Ottenkamp J, Bilardo CM. Audit of 10 years of referrals for fetal echocardiography. Prenat Diagn. 2011;31(12):1134-1140.

8. Garne E, Stoll C, Clementi M; Euroscan Group. Evaluation of prenatal diagnosis of congenital heart diseases by ultrasound: experience from 20 European registries. Ultrasound Obstet Gynecol. 2001;17(5): 386-391.

9. Hoffman JI. Incidence of congenital heart disease: II. Prenatal incidence. Pediatr Cardiol. 1995;16(4):155-165.

10. Hoffman JI. Incidence of congenital heart disease: I. Postnatal incidence. Pediatr Cardiol. 1995;16(3):103-113.

11. Allan L. Prenatal diagnosis of structural cardiac defects. Am J Med Genet C Semin Med Genet. 2007;145C(1):73-76.

12. Stumpflen I, Stumpflen A, Wimmer M, Bernaschek G. Effect of detailed fetal echocardiography as part of routine prenatal ultrasonographic screening on detection of congenital heart disease. Lancet. 1996;348(9031):854-857.

13. Viñals F, Poblete P, Giuliano A. Spatio-temporal image correlation (STIC): a new tool for the prenatal screening of congenital heart defects. Ultrasound Obstet Gynecol. 2003;22(4):388-394.

14. Gonçalves LF, Lee W, Chaiworapongsa T, et al. Four-dimensional ultrasonography of the fetal heart with spatiotemporal image correlation. Am J Obstet Gynecol. 2003;189(6):1792-1802.

15. DeVore GR, Falkensammer P, Sklansky MS, Platt LD. Spatio-temporal image correlation (STIC): new technology for evaluation of the fetal heart. Ultrasound Obstet Gynecol. 2003;22(4):380-387.

16. Lee W, Gonçalves LF, Espinoza J, Romero R. Inversion mode: a new volume analysis tool for 3-dimensional ultrasonography. J Ultrasound Med. 2005;24(2):201-207.

17. Gonçalves LF, Lee W, Espinoza J, Romero R. Examination of the fetal heart by four-dimensional (4D) ultrasound with spatio-temporal image correlation (STIC). Ultrasound Obstet Gynecol. 2006;27(3): 336-348.

18. Turan S, Turan OM, Ty-Torredes K, Harman CR, Baschat AA. Standardization of the first-trimester fetal cardiac examination using spatiotemporal image correlation with tomographic ultrasound and color Doppler imaging. Ultrasound Obstet Gynecol. 2009;33(6):652-656.

19. Espinoza J. Contemporary clinical applications of spatio-temporal image correlation in prenatal diagnosis. Curr Opin Obstet Gynecol. 2011;23(2):94-102.

20. Paladini D. Standardization of on-screen fetal heart orientation prior to storage of spatio-temporal image correlation (STIC) volume datasets. Ultrasound Obstet Gynecol. 2007;29(6):605-611.

21. Espinoza J, Kusanovic JP, Gonçalves LF, et al. A novel algorithm for comprehensive fetal echocardiography using 4-dimensional ultrasonography and tomographic imaging. J Ultrasound Med. 2006;25(8): 947-956.

22. DeVore GR, Polanco B, Sklansky MS, Platt LD. The 'spin' technique: a new method for examination of the fetal outflow tracts using threedimensional ultrasound. Ultrasound Obstet Gynecol. 2004;24(1): $72-82$. 
23. Uittenbogaard LB, Haak MC, Spreeuwenberg MD, van Vugt JM. Fetal cardiac function assessed with four-dimensional ultrasound imaging using spatiotemporal image correlation. Ultrasound Obstet Gynecol. 2009;33(3):272-281.

24. Gindes L, Hegesh J, Weisz B, Gilboa Y, Achiron R. Three and four dimensional ultrasound: a novel method for evaluating fetal cardiac anomalies. Prenat Diagn. 2009;29(7):645-653.

25. Nardozza LM, Rolo LC, Araujo Júnior E, et al. Reference range for fetal interventricular septum area by means of four-dimensional ultrasonography using spatiotemporal image correlation. Fetal Diagn Ther. 2013;33(2):110-115.

26. Araujo Júnior E, Rolo LC, Simioni C, et al. Comparison between multiplanar and rendering modes in the assessment of fetal atrioventricular valve areas by 3D/4D ultrasonography. Rev Bras Cir Cardiovasc. 2012;27(3):472-476.

27. Rolo LC, Nardozza LM, Araujo Júnior E, et al. Reference ranges of atrioventricular valve areas by means of four-dimensional ultrasonography using spatiotemporal image correlation in the rendering mode. Prenat Diagn. 2013;33(1):50-55.

28. Rolo LC, Marcondes Machado Nardozza L, Araujo Júnior E, Simioni C, Maccagnano Zamith M, Fernandes Moron A. Reference curve of the fetal ventricular septum area by the STIC method: preliminary study. Arq Bras Cardiol. 2011;96(5):386-392.

29. Gonçalves LF, Espinoza J, Romero R, et al. Four-dimensional ultrasonography of the fetal heart using a novel tomographic ultrasound imaging display. J Perinat Med. 2006;34(1):39-55.

30. Hata T, Tanaka H, Noguchi J, Dai SY, Yamaguchi M, Yanagihara T. Four-dimensional volume-rendered imaging of the fetal ventricular outflow tracts and great arteries using inversion mode for detection of congenital heart disease. J Obstet Gynaecol Res. 2010;36(3):513-518.

31. Pooh PK, Korai A. B-flow and B-flow spatio-temporal image correlation in visualizing fetal cardiac blood flow. Croat Med J. 2005;46(5): 808-811.

32. Zhang M, Pu DR, Zhou QC, Peng QH, Tian LQ. Four-dimensional echocardiography with B-flow imaging and spatiotemporal image correlation in the assessment of congenital heart defects. Prenat Diagn. 2010;30(5):443-448.

33. Yeo L, Romero R, Jodicke C, et al. Four-chamber view and "swing technique" (FAST) echo: a novel and simple algorithm to visualize standard fetal echocardiographic planes. Ultrasound Obstet Gynecol. 2011;37(4):423-431.

34. Molina FS, Faro C, Sotiriadis A, Dagklis T, Nicolaides KH. Heart stroke volume and cardiac output by four-dimensional ultrasound in normal fetuses. Ultrasound Obstet Gynecol. 2008;32(2):181-187.
35. Simioni C, Araujo Júnior E, Martins WP, et al. Fetal cardiac output and ejection fraction by spatio-temporal image correlation (STIC): comparison between male and female fetuses. Rev Bras Cir Cardiovasc. 2012;27(2):275-282.

36. Simioni C, Nardozza LM, Araujo Júnior E, et al. Heart stroke volume, cardiac output, and ejection fraction in 265 normal fetus in the second half of gestation assessed by 4D ultrasound using spatio-temporal image correlation. J Matern Fetal Neonatal Med. 2011;24(9):1159-1167.

37. Simioni C, Nardozza LM, Araujo Júnior E, et al. Fetal cardiac function assessed by spatio-temporal image correlation. Arch Gynecol Obstet. 2011;284(1):253-260.

38. DeVore GR. Assessing fetal cardiac ventricular function. Sem Fetal Neonatal Med. 2005;10(6):515-541.

39. Tongsong T, Wanapirak C, Piyamongkol W, et al. Fetal ventricular shortening fraction in hydrops fetalis. Obstet Gynecol. 2011;117(1): 84-91.

40. Araujo Júnior E, Rolo LC, Nardozza LM, Moron AF. Fetal cardiac evaluation by 3D/4D ultrasonography (STIC): what is its real applicability in the diagnosis of congenital heart disease? Rev Bras Cir Cardiovasc. 2013;28(1):III-V.

41. Bennasar M, Martinez JM, Olivella A, et al. Feasibility and accuracy of fetal echocardiography using four-dimensional spatiotemporal image correlation technology before 16 weeks' gestation. Ultrasound Obstet Gynecol. 2009;33(6):645-651.

42. Yagel S, Cohen SM, Rosenak D, et al. Added value of three-/fourdimensional ultrasound in the offline analysis and diagnosis of congenital heart disease. Ultrasound Obstet Gynecol. 2011;37(4):432-437.

43. Espinoza J, Lee W, Comstock C, et al. Collaborative study on 4-dimensional echocardiography for the diagnosis of fetal heart defects: the COFEHD study. J Ultrasound Med. 2010;29(11):1573-1580.

44. Kagan KO, Pintoffl K, Hoopmann M. First-trimester ultrasound images using HDlive. Ultrasound Obstet Gynecol. 2011;38(5):607.

45. Araujo Júnior E, Nardozza LM, Moron AF. Three-dimensional ultrasound STIC-HDlive rendering: new technique to assessing of fetal heart. Rev Bras Cardiovasc Cir. 2013;28(4):5-7.

46. Hata T, Mashima M, Ito M, Uketa E, Mori N, Ishimura M. Threedimensional HDlive rendering images of the fetal heart. Ultrasound Med Biol. 2013;39(8):1513-1517.

47. Grisolia G, Tonni G. Fetal echocardiography using HDlive. J Obstet Gynecol Can. 2013;35(6):497-498.
International Journal of Women's Health

\section{Publish your work in this journal}

The International Journal of Women's Health is an international, peerreviewed open-access journal publishing original research, reports, editorials, reviews and commentaries on all aspects of women's healthcare including gynecology, obstetrics, and breast cancer. The manuscript management system is completely online and includes

\section{Dovepress}

a very quick and fair peer-review system, which is all easy to use. Visit http://www.dovepress.com/testimonials.php to read real quotes from published authors. 